\title{
Incrementalism and Structural Change: A Technical Note
}

\author{
SYED NAWAB HAIDER NAQVI and ASGHAR QADIR*
}

\begin{abstract}
In the pursuit of social justice, the problem of relative economic inequality in developing countries deserves serious consideration. With the help of a formal analytical framework, the present paper shows that the essential elements of a solution of the problem are structural change, focusing on narrowing down the difference in initial wealth holdings, and an active 'incrementalist' policy of keeping the growth rate of the income of the poor significantly higher than the growth rate of the income of the rich. Naive egalitarianism, requiring only the equality of these two growth rates in the name of moderation, will only create an explosive situation in which economic inequality will keep on increasing. It is further argued that in the context of solving the problem the critical points are the ones where the income and wealth gaps begin to narrow down. Once these points are reached, relative inequality will be finally eliminated in a fairly short time regardless of the relative size of the initial wealth holdings. Policy action to achieve the stated objective will require a marriage of structural change and incrementalism rather than an emphasis on one to the neglect of the other.
\end{abstract}

The spectacle of strident poverty flying in the face of the respectable growth rates scored by developing countries has recurred in the growing literature on development economics. Whether the macabre spectacle is merely a figment of imagination or is a true characterization of the objective reality on the ground has been long debated by development economists, who nevertheless agree that acute poverty in the developing countries is a reality.

What is poverty and how should it be measured have, again, been points of active, even acrimonious, debate among the development economists. Absolute inequality and relative inequality are the two basic concepts used to comprehend the problem of poverty. The former is measured by employing poverty lines, drawn both differently and indifferently by different economists, ${ }^{1}$ while the latter attempts

*The authors are, respectively, Director, Pakistan Institute of Development Economics (PIDE), Islamabad, and Associate Professor of Mathematics, Quaid-i-Azam University, Islamabad. Dr. Qadir is also Research Associate at the PIDE. They wish to thank especially Professors Jan Tinbergen and H. C. Bos for their highly perceptive comments. The authors also gratefully acknowledge the useful suggestions made by Professors Gunnar Fl $\phi$ ystad, Pan Yotopoulos and Ake G. Blomqvist. Needless to add, only the authors bear the responsibility for any errors that may still be there.

${ }^{1}$ Sen $[15]$ has shown that the concept of poverty line as a measure of absolute inequality is totally inadequate, even misleading. This poverty measure violates both the "monotonicity axiom" and the "transfer axiom": it is insensitive to a reduction in the number of persons below the poverty line as well as to a pure transfer of income from a person below the poverty line to anyone who is richer. 
to measure the phenomenon of relative deprivation of the poorer sections of the society. An influential view among economists has been that absolute poverty is the real thing to be concerned about, particularly at the very low levels of income that characterize developing countries. When substantial parts of the population in such economies face starvation and utter deprivation, the more immediate problem is that of giving the poor people something which, for them, is better than nothing. According to this view, poor people have no time or strength to play the dog-inthe-manger game. While there is an undeniable element of truth in this point of view, the fact remains that, as Veblen [19] and Duesenberry [8] tell us, consumption functions are typically interdependent so that people do worry about both what they are getting and consuming and how much they get and consume in relation to others. ${ }^{2}$ This concern is most likely to turn into an obsession when the differences in relative economic well-being are as great as are widely prevalent in the developing countries, especially where the basic economic structure is feudalistic. ${ }^{3}$

Partly for this reason, we should be concerned not only with the income share of the poor at a given point in time, but also with how, given the size of initial wealth holdings, this share grows over time. In the literature, oblique references have been made to the importance of each of these concepts. For instance, Paul Baran [4] and many others have emphasized the importance, from social and economic points of view, of changing the feudal-capitalistic structure of the poor economies where wealth, held mostly in the form of land, is very unequally distributed between the rich and the poor. ${ }^{4}$ In the same vein, Irma Adelman [1] has advocated a "radical asset redistribution, focusing primarily on land" as a precondition of achieving "equitable economic growth". Then there are empirical studies, such as [3], which emphasize an equitable distribution of initial wealth holdings as the key factor explaining the somewhat unusual phenomenon of growth and equity going hand in hand in highgrowth developing economies like South Korea and Taiwan. On the other hand, Chenery et al. [7], while clearly recognizing the connection between initial wealth holdings and the 'existing' levels of relative inequality, argue that the only feasible policy most likely to bear fruit is the one that aims at ensuring that the marginal

${ }^{2}$ The Duesenberry relative-income hypothesis, which highlights the interdependence of individual consumption behaviour and its irreversibility over time, has been found to explain the consumption behaviour not only in developed countries but in developing countries as well. See Singh and Kumar [16]. Furthermore, as Hirschman and Rothsehild [11] show, while [relative inequatities may be tolerated in the [relative] inequalities may be tolerated in the early stages of development, such tolerance will diminish sharply once the poor realize that their expectations about eventually catching up with the rich are not going to be fulfilled.

${ }^{3}$ Empirical evidence suggests that the magnitude of relative inequality is, on average greater in the developing countries than in the developed countries. Also, the variance around the average is larger in the former than in the latter. See Chenery et al. [7, p. 7].

${ }^{4}$ See Naqvi $[13]$ for a statement of such a point of view. increments in the income and wealth are equitably distributed..$^{5}$ How equitably, remains an open issue.

What is not always clearly spelt out in the development literature is the set of definite (algebraic) relationships that must hold between initial relative wealth holdings and the growth rates of the incomes of the rich and the poor. Also not sufficiently understood is the point that in the event of the non-fulfilment of these relationships relative inequality will keep on increasing even if incremental changes in income and wealth are redistributed more equitably than in the 'past'. Indeed, the gap between the rich and the poor will not even begin to narrow down if these relationships are not satisfied. These are important considerations because they show that the iron law of inequality will continue to defeat the complaisant policy initiatives of the 'incrementalists'. Relative inequality is sustained, even exacerbated, by a set of policies and institutions that promote large inter-class differences in wealth holdings and a higher relative growth rate of the income of the rich as compared with that of the income of the poor. This state of affairs must be reversed by changing the relevant institutions and by revising the set of rules whereby the rich and the poor are rewarded by the society. A "critical minimum effort" must be made to face the problem of relative inequality squarely in the face. Incidentally, here we have a case of market failure, requiring the Visible Hand of the government to set things right. ${ }^{6}$ Needless to state, we assume here that the government is a popularly elected one and inclined towards structural change.

The present paper focuses on the problem of relative economic inequality, and spells out a set of algebraic relationships relating the size of initial wealth holdings to the relative growth rates of incomes for determining the changes in the level of relative inequality over time. The basic model, which essentially presents the algebra of wealth and income gaps, is set out in Section II. To see the magnitude of the problem and to evaluate the relative merits of alternative solution(s), a numerical illustration is given in Section III. The main policy implications of the analysis are briefly discussed in Section IV.

In most of the developing countries, initial differences in wealth holdings, which are typically much larger than income differences, keep the size of the relative

${ }^{5}$ See also Chenery [6] where he observes: "Measures to redistribute increments in income and new asset formation are more likely to be acceptable [than a] redistribution of the existing assets ..."p. 313 .

${ }^{6}$ See Adelman and Morris [2] on this point: "The poorest segments of the population typically benefit from economic growth only when government plays an active part ." 
inequality also large because they dominate income flows. ${ }^{7}$ It should then be intuitively obvious that, without a substantial redistributive effort aimed at offsetting it, relative inequality would grow with the passage of time. What is not so obvious is the precise relationship between the initial size of relative wealth holdings and the magnitude of relative growth rates of income coming from initial wealth holdings and from other sources. ${ }^{8}$ Nor is it clear how government policy should impinge on these two magnitudes to narrow income and wealth differences over a specified time.

For meaningful policy-making, one ought to know the orders of magnitude of the two processes that must go on simultaneously to make a successful assault on the problem within a reasonable time period. This last consideration is important because the mere knowledge that a specific set of policies will solve the inequality problem in, say, 100 years is not of much use either economically or politically. A formal analytical framework is required to make these matters clear.

For expositional clarity, let us first assume that a developing economy is sharply divided between the rich and the poor, whose initial wealth holdings are given by $A$ and $B$, while $a$ and $b$ denote the rates of growth of income of the rich and the poor respectively. ${ }^{9}$ Furthermore, the relative growth rates of wealth and income are assumed to be a function exclusively of their initial wealth holdings. This restrictive assumption is then relaxed to allow for income from other sources as well in order to gauge the effectiveness of conscious policy action in reducing over time the size of relative inequality emanating from initial asset holdings. It should be intuitively obvious that the course of 'history' can be changed by manipulating $A$ and $B$ as well as $a$ and $b$. If, as is the case, wealth is more unequally distributed than income, a reduction in wealth differences should reduce relative inequality regardless of what the relative shares of the rich and the poor in total wealth are. Relative inequality will be reduced even more quickly if the values assigned to $b$ are higher than those assigned to $a$.

To highlight the basic ingredients of the 'solution' to the problem of relative inequality, four theorems and three corollaries are spelt out. It will be seen that the

${ }^{7}$ In a recent study [9], Ercelawn reports that in Pakistan while the Gini Coefficients of farm holdings and of land ownership are 0.64 and 0.78 respectively, the Gini Coefficient of income among rural households is 0.32 , which itself is quite high.

${ }^{8}$ It should be noted that income and wealth differences may be strongly correlated, especially in the developing countries, where, as noted in the text, the differences in initial wealth holdings are very large. Yet, for analytical reasons it is important to keep the two differences apart to bring out sharply the policy issues involved in making suitable corrections in the two gaps. Typically, structural reforms are harder to implement.

Wealth may be broadly defined to include both physical wealth and the stock of human kill in the initial period. Such a broad definition has the advantage of bringing the initial bias skingt the poor into a comprehensive set of against the poor into a sharp focus and also of pointing to the need for a condings of the rich policies aimed
and the poor. 'story' as we tell it is somewhat more complicated than is relayed to us by intuition and is for that reason worth telling in detail.

Theorem I: Let $A$ and $B$ be initial wealth holdings such that $A>B$, and let their respective growth rates be $a$ and $b$. Relative inequality ${ }^{10}$ will decrease iff $b>a$.

Proof: At any time $t$, the respective wealth holdings of $P_{1}$ and $P_{2}$ are:

$$
W_{1}(t)=A e^{a t}, W_{2}(t)=B e^{b t}
$$

The wealth gap is then

$$
w(t)=A e^{a t}-B e^{b t}
$$

Initially we see that

$$
w(o)=A-B>0 .
$$

For the wealth gap to become zero at some time $\bar{t}$, we require that

$$
\begin{aligned}
A e^{a \bar{t}} & =B e^{b \bar{t}}, \\
\therefore \quad \bar{t} & =\frac{\ln (A / B)}{b-a} .
\end{aligned}
$$

Now the numerator is a positive quantity as $A>B$. For $\bar{t}$ to be a finite positive time, we require that $b>a$, since by equation (1)

$$
\bar{t} \rightarrow \infty \quad \text { as } \quad b \rightarrow a .
$$

This theorem makes the basic point that the problem of relative inequality is solvable if and only if the rate of growth of wealth is higher for the poor than for the rich.

Theorem II: Assuming that relative inequality is exclusively a function of initial wealth holdings, a necessary and sufficient condition for the wealth gap to be decreasing is

$$
A / B<b / a
$$

${ }^{10}$ The relative inequality, defined as $W_{1}(t) / W_{2}(t)$, will increase or decrease according as the wealth gap, $W_{1}(t)-W_{2}(t)$, is positive or negative. 
Proof: The wealth gap will be extremized if

$$
\dot{w}(t)=d w(t) / d t=0
$$

Thus, if it is to be extremal at $t^{*}$, we require that

$$
\begin{aligned}
a A e^{a t *} & =b B e^{b t *}, \\
\therefore \quad & t^{*}=\frac{\ln (a A / b B)}{b-a} .
\end{aligned}
$$

Now, if $t>t^{*}$, let us put $t=t^{*}+\Delta t$.

$$
\therefore \quad \dot{w}(t)=a A e^{a t *} e^{a \Delta t}-b B e^{b t *} e^{b \Delta t},
$$

which, using equation (2), gives

$$
\dot{w}(t)=a A e^{a t *}\left(e^{a \Delta t}-e^{b \Delta t}\right) . \quad \ldots \quad \ldots \quad \text { by equation (2) }
$$

Since $b>a, \dot{w}(t)<0$, i.e. the wealth gap is decreasing over time after time $t^{*}-$ i.e. it is maximal at $t=t^{*}$. For the gap to decrease from the present time, we require that $t^{*}<0$.

Putting this criterion into equation (2), we require that

$$
\ln (a A / b B)<0
$$

Thus we require that

$$
A / B<b / a
$$

$$
\begin{array}{llll}
\cdots & \cdots & \cdots & \cdots
\end{array}
$$

Corollary: For the wealth gap to be non-increasing from the present time,

$$
A / B \leqslant b / a
$$

Thus the least condition for the gap to be non-increasing from the present is

$$
A / B=b / a
$$

poor is less than (or at least equal to) the inverse ratio of the growth rates of their incomes.

We now relax the assumption made so far - that relative inequality is a function exclusively of the initial wealth holdings - and allow for income resulting from work effort and sources other than wealth holdings. Assume for simplicity that the total income from all sources is proportional to the rate of return on wealth, $\dot{W}(t)$, and is represented by a constant of proportionality, $\alpha$, for all levels of initial wealth holdings. Then,

$$
I(t) \quad=\alpha \dot{W}(t)
$$

Since some of the total income will be consumed, $\alpha$ is greater than 1 if the consumption is less than income from sources other than wealth; otherwise it will be less than 1 . In any case, $\alpha>0$.

Theorem III: Assuming that total income is proportional to the rate of return on wealth, a necessary and sufficient condition for the income gap to decrease is that

$$
A / B<(b / a)^{2}
$$

Proof: The income gap is given by

$$
\begin{aligned}
i(t) \quad & =I_{1}(t)-I_{2}(t) \\
& =\alpha \dot{w}(t) .
\end{aligned}
$$

For the income gap to be extremized at the time $t^{\dagger}$

$$
\left.\alpha \ddot{w}(t)\right|_{t=t^{\dagger}}=0 .
$$

As before, this gives

$$
t^{\dagger}=\frac{\ln \left(a^{2} A / b^{2} B\right)}{b-a} .
$$

Again, as before, $i(t)$ will decrease for $t>t^{\dagger}$. Thus $i(t)$ is maximal at $t=t^{\dagger}$.

What this important theorem and the corollary say is that relative inequality will be decreasing (non-increasing) only if the ratio of wealth holdings by the rich and the 
For the gap to decrease from the present,

$$
\ln \left(a^{2} A / b^{2} B\right)<0
$$

whence

$$
A / B<(b / a)^{2} .
$$$$
\begin{array}{lll}
\cdots & \cdots & \cdots
\end{array}
$$

It should be noted that if $\alpha$ were an increasing (decreasing) function of initial wealth holdings, $t^{\dagger}$ would increase (decrease).

Corollary: For the income gap to be non-increasing,

$$
A / B \leqslant(b / a)^{2} .
$$

Hence, a least condition for the gap to be non-increasing from the present is

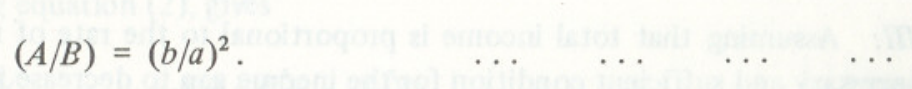

These results show that the main message of Theorem II (and the Corollary) remains substantially unchanged even if we allow for income from sources other than initial wealth holdings, with the difference that when dealing with income gap we relate the ratio of wealth holdings to the square of the inverse ratio of growth rates of income. Note that, by Theorem I, for this result to hold, the income of the poor must rise faster than the income of the rich. (The orders of magnitude involved are estimated in the next section.)

We now consider the question of eliminating, not just reducing, relative inequality

Theorem IV: The time interval between the start of a decrease in the wealth and income gaps and the closing of those gaps depends only on the values of $a$ and $b$, and is independent of initial wealth holdings.

Proof: Using equations (1) and (2),

$$
\bar{t}-t^{*}=\frac{\ln (b / a)}{b-a},
$$

such that the time interval is independent of $A$ and $B$. Again, using equations (2) and (3),

$$
t^{*}-t^{\dagger}=\frac{\ln (b / a)}{b-a}
$$

This time interval is also independent of $A$ and $B$.
Corollary: Using equations (1) and (6), we see that the following result also holds:

$$
1-t^{*} / \bar{t}=\frac{\ln (b / a)}{\ln (A / B)} . \quad \ldots \quad \ldots \ldots \ldots
$$

It follows from equations (1), (2) and (8) that we can make $t^{*}$ reasonably small compared with $\bar{t}$ only if the ratio of the growth rates is logarithmically comparable with the ratio of initial wealth holdings.

\section{III}

Equations (1) to (8) above give a fairly exhaustive set of conditions for relative inequality to decrease over time till it is finally eliminated, and make it clear that this objective is achievable, within a reasonable time frame, if and only if the initial wealth is redistributed through suitable structural reforms and the rate of increase of the income of the poor is kept always higher than the rate of increase of the income of the rich. If either of these conditions is not satisfied, relative inequality will continue to grow indefinitely over time, even if the current income of the poor rises at a rate equal to that of the current income of the rich. It is also clear from equations (7) and (8) that once relative inequality starts to decrease, the job of finishing it off altogether is relatively easy in that the size of initial wealth holdings becomes redundant at this stage and only the relative growth rates of incomes of the rich and the poor matter. The way to the "state of bliss" passes through the purgatory of structural reforms and a stiff income distribution policy. ${ }^{11}$

These propositions can best be elucidated with an arithmetic example. Let the initial wealth of the poor, $B$, be fixed at Rs. 10,000 and the growth rate of the income of the rich, $a$, at 10 percent per annum. The initial wealth of the rich, $A$, is then successively reduced through suitable structural reform from Rs. 1,000,000 through Rs. 316,228 to Rs. 100,$000 ;^{12}$ and, as required by Theorem I, the wealth of the poor is allowed to grow at annual rates of 10 percent, 11 percent, 12 percent, 15 percent and 20 percent, each of which is equal to or greater than $a$ (10 percent). ${ }^{13}$ These policy alternatives can be evaluated by considering the length of time each of

\footnotetext{
${ }^{11}$ An optimal fiscal policy to implement the programme of action indicated in the text will have to be such as equalizes the marginal utilities of income among individuals. For a formal derivation of such a rule, see Tinbergen [18]. Assuming diminishing marginal utility of income, the degree of progressivity embedded in the optimal system will depend on the pre-existing income (and wealth) differences between the rich and the poor.

${ }^{12}$ The process of redistribution of asset holdings dealt with in the numerical example makes clear the redistributive mechanism implicit in the mathematical model given in Section II where the conditions required to close the income and wealth gaps are specified.

${ }^{13}$ In these illustrative examples, the growth rates have been taken to be unrealistically large to bring the time for closing the wealth gap to a more reasonable value. For lower growth
} rates, the corresponding time would be even greater. 
these policies takes to reach $t^{*}, t^{\dagger}$, and $\bar{t}$, which correspond, respectively, to the critical points for the wealth gap and income gap to narrow down and for these two gaps to be finally eliminated. ${ }^{14}$ It should clearly be the aim of the government policy to reach $t^{*}$ or $t^{\dagger}$ in the shortest period of time. Thus the government can (and should) decide on the values of $A$ and $b$ corresponding to the feasible values of $t^{*}$ or $t^{\dagger}$. On the other hand, the values of $t^{*}$ or $t^{\dagger}$ can also be chosen in view of the feasibility of assigning appropriate values to $A$ or $b$ or both.

A look at Table 1 makes clear which the 'winning' combinations are. We distinguish five cases corresponding to the five values of $b$ and three values of $A$. Case I, read horizontally, shows that if the growth rates $a$ and $b$ are equal, it will take an infinite number of years to reach $t^{*}$. Assuming that the society has set its heart on reaching the state of bliss in a reasonably short period of time, this policy is clearly ruled out. This case is also illustrated in Figure 1, which shows the 'explosive' outcome of a policy that only keeps $a=b$ and no more: a gap of Rs. 0.09 million at $t=0$ swells to Rs. 0.665 million at $t=20$. This is an instance of 'naive egalitarianism'. It is naive because its inequality-reducing results will never become apparent.

Cases II and III, again read horizontally, bring out in sharp relief the shortcomings of a policy, such as advocated by Chenery [6], of 'mild incrementalism', combined with a policy of redistribution of wealth whereby the difference between $A$ and $B$ is successively decreased from 100 times to 32 times and then to 10 times. With such a policy package, with $A$ set at Rs. 100,000 , it will take at least a century to reach $t^{*}$ or $t^{\dagger}$ if the difference between the growth rates $a$ and $b$ is only 1 percent or 2 percent! It is the Keynesian long run in which we shall long be dead. This policy option is again pointless, if only because 'other things' do not remain unchanged for such a long period of time.

Recognizing that both naive egalitarianism and mild incrementalism are no more than quixotic sallies at the inequality windmill, Cases IV and V offer the only meaningful choices open to the policy-makers. The growth path corresponding to Case V illustrates a 'successful' policy, where the rate of growth of $b$ is double that of the no-win Case I. In this case, with $A=$ Rs. $100,000, t^{\dagger}$ will be reached in 9 years, $t^{*}$ in 16 years and $\bar{t}$ in 23 years. This case is shown in Figure 1. Under the most skewed distribution of initial wealth holdings, with $A=$ Rs. 100,000 , the time it takes to reduce relative inequality does not exceed 40 years. However, such a result cannot be brought about easily because to raise $b$ to 20 percent from 10 percent,

${ }^{14}$ From equations (6) and (7), it follows that $\bar{t}-t^{*}=t^{*}-t^{\dagger}$. In other words, if we know the time it takes to go from the income-gap decline point to the wealth-gap decline point, ke will know the len the point when this gap is finally closed. Also, by Theorem IV, the values in the last column of Table 1 are independent of the initial wealth differences.

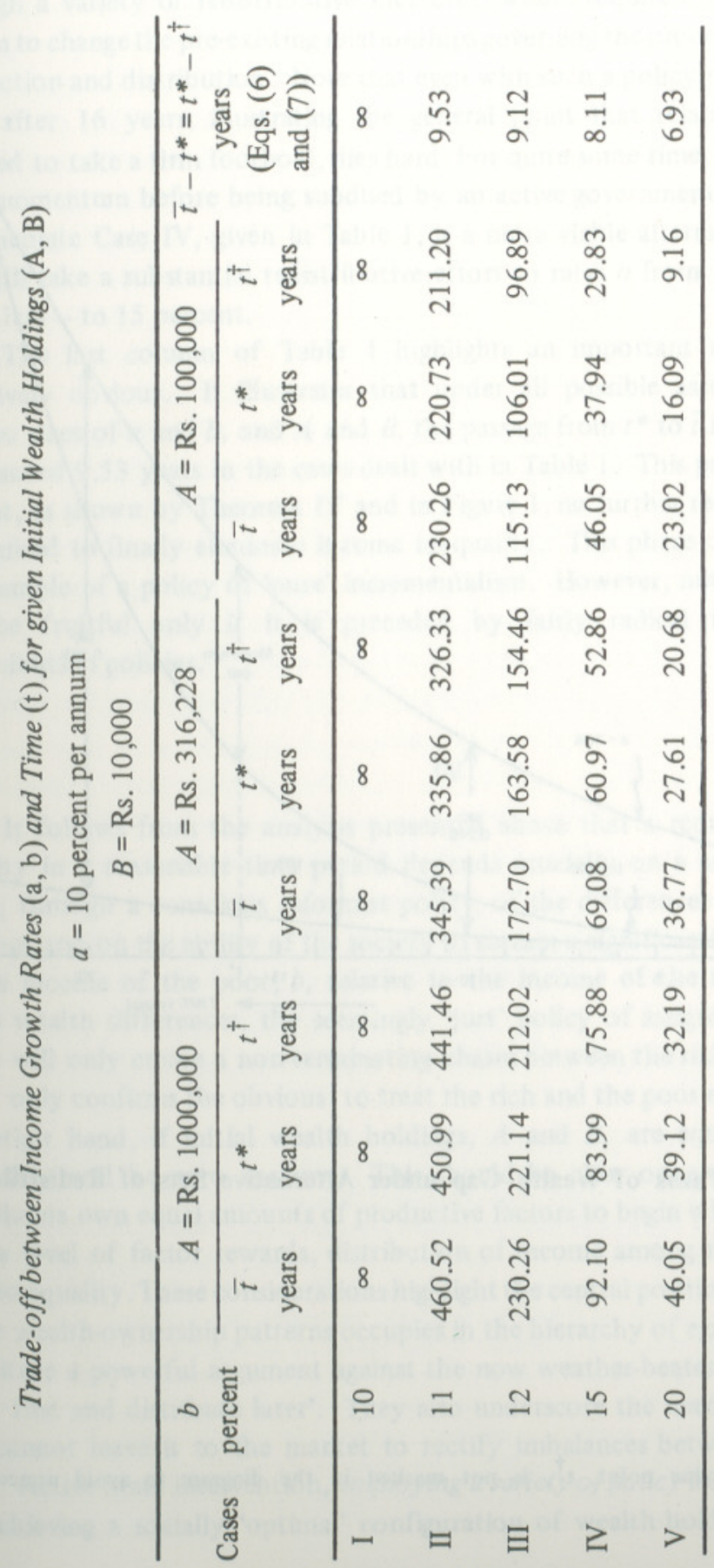


rates of income and the distribution of income in a growing economy. A hard remedy this, but what cannot be avoided must be faced with equanimity. ${ }^{15}$

Having seen the dark side of the 'moon', one may question, as the proponents of the basic-needs philosophy do, even the relevance of the concept of relative inequality in the context of the problem of evolving a viable anti-poverty programme. Paul Streeten [17] poses the choice between "a reduction in income inequality and basic needs", ${ }^{16}$ and votes for the latter. While meeting the basic needs of the poorest people is an effective and a politically feasible way of transferring real resources from the rich to the poor, it is hard to understand why this transfer process must stop at meeting basic needs and not go any further to reduce relative inequality, the incidence of which is much higher in developing countries than in developed countries. The economists and policy-makers may satisfy their conscience by drawing a parallel between the relative inequality across rich and poor countries and that between rich and poor people within the country, and argue that what is not good for the goose is also not good for the gander. ${ }^{17}$ However, this is a false analogy because while it is impossible to redistribute the assets held by rich countries in favour of the poor countries, the same can (and should) be done for different classes within the same country. Furthermore, while the envy of a poor nation for a rich nation may produce only frustration, the envy of the poor for the rich may upset the applecart by provoking, in extreme cases, a social revolution.

That being the case, it is a reasonable assumption to make that a reduction of inequality is a desirable social objective, and that in so far as a higher degree of relative inequality signifies a lower level of welfare for a given total income, every move towards lesser inequality tends to increase social welfare. It should also be clear by now that structural change, focusing on reducing wealth differences not only in the initial period but in 'subsequent' periods as well, is an essential means of achieving this objective. This will require the government to initiate meaningful redistributive measures, especially effective land reforms, as a substantial part of total

${ }^{15}$ See Adelman [1] for a similar point of view: "The price of equity is high: a necessary condition for its achievement is radical structural change" (p. 303).

${ }_{17}^{16}$ For a forceful exposition of the basic-needs approach, see Haq [10].

${ }^{17}$ As to the former type of relative inequality, Morawetz [12] has shown that between 1950 and 1975 not a single developing country (apart from Libya) succeeded in narrowing the (absolute) gap between its GNP per capita and the average GNP per capita of the OECD countries. Indeed, in many cases the gap doubled! Incidentally, Morawetz has explained this apparent paradox, without a formal proof, by reference to the failure of developing countries to raise to equality the ratio of their per capita incomes to those of the OECD countries with the inverse ratio of their growth rates. This condition resembles the one established by the corollary of Theorem II, but note that the context is different. Whereas Morawetz's observation concerns inter-country income inequalities, the present paper explores the relationship between the rich and the poor within the same country. Also, the relation between wealth holding and income holding is not recognized in Morawetz's observations. wealth in developing countries is held in the form of land.$^{18}$ However, this is not enough. Additional redistributive measures, e.g. progressive taxation, an elaborate social security programme, etc., will have to be taken to transfer enough resources to the poor so that the rate of growth of their marginal incomes remains substantially higher than that of the marginal incomes of the rich. Furthermore, 'appropriate' technological change must be promoted so that the reward of the abundant factor rises relative to that of the scarce factor. In labour-surplus developing countries, this would mean a rise in wages relative to rentals. Then, through the spread of education to the poorer sections of the society, the initial difference in skills will also have to be narrowed down.

That in the pursuit of 'happiness' glaring relative inequalities will have to be removed should be clear enough. As Sen [14] has remarked, "a perceived sense of inequity is a common ground of rebellion". This is important. The fact that incomes of all, the rich and the poor, are rising over time does not by itself guarantee happiness to the poor. It is also not a sure-fire recipe against social upheavals. In other words, a continuous rise in the income of all sections of the society is a necessary but not a sufficient condition for achieving social 'stability' which comes from a "perceived sense" of sharing in economic prosperity, actual and potential. Such a perception will be satisfied if, as initial wealth differences are reduced, the income of the poor rises at a rate significantly faster than that of the income of the rich. A marriage of incrementalism and structural change, as proposed in this paper, holds out the best hope that, notwithstanding a stiff resistance from the vested-interest class against such a matrimony, a happier society will be born through this union.

\section{REFERENCES}

1. Adelman, Irma. "Development Economics - A Reassessment of Goals". American Economic Review (Papers and Proceedings). Vol. LXV, No. 2. May 1975.

2. Adelman, Irma, and C. T. Morris. Economic Growth and Social Equity in Developing Countries. Stanford, Calif.: Stanford University. 1973.

3. Ahluwalia, M. S. "Inequality, Poverty and Development". Journal of Development Economics. Vol. 3, No. 3. 1976.

${ }^{18}$ Berry and Cline [5] show that agricultural productivity is negatively related to the largesized farm holdings prevailing in the developing countries so that a reduction in the average size of farm holdings will increase agricultural productivity. Here we have a clear example of a situation where a reduction in inequality increases social welfare without impairing the growth potential of the economy. 
4. Baran, Paul. Political Economy of Growth. New York: Monthly Review Press. 1957.

5. Berry, R. Albert, and William R. Cline. Agrarian Structure and Productivity in Developing Countries. Baltimore: Johns Hopkins University Press. 1979.

6. Chenery, Hollis B. "The Structuralist Approach to Development Policy". American Economic Review (Papers and Proceedings). Vol. LXV, No. 2. May 1975.

7. Chenery, Hollis B., et al. Redistribution with Growth. New York: Oxford University Press. 1974.

8. Duesenberry, James. Income, Saving and the Theory of Consumer Behaviour. Cambridge, Mass.: Harvard University Press. 1949.

9. Ercelawn, Aly. "Income Inequality in Rural Pakistan: A Case Study of Sample Villages". Pakistan Journal of Applied Economics. Vol. III, No. 1. Summer 1984.

10. Haq, Mahbub ul. The Poverty Curtain. New York: Columbia University Press. 1976.

11. Hirschman, Albert O., and Michael Rothschild. "Changing Tolerance for Inequality in Development”. Quarterly Journal of Economics. Vol. LXXXVII, No. 4. November 1973.

12. Morawetz, David. Twenty-Five Years of Economic Development (1950-1975). Washington, D.C.: The World Bank. 1977.

13. Naqvi, Syed Nawab Haider. "Development Economists in "Emperor's Clothes"?" Pakistan Development Review. Vol. XXIII, Nos. 2-3. SummerAutumn 1984.

14. Sen, A. K. On Economic Inequality. Oxford: Clarendon Press. 1973.

15. Sen, A. K. "Poverty: A Cardinal Approach to Measurement". Econometrica. Vol. 44. March 1976.

16. Singh, Balvir, and Romesh E. Kumar. "The Relative Income Hypothesis - A Cross-Country Analysis". Review of Income and Wealth. Series. 17, No. 4. December 1971.

17. Streeten, Paul. First Things First. New York: Oxford University Press. 1981.

18. Tinbergen, Jan. "A Positive and a Normative Theory of Income Distribution". Review of Income and Wealth. Series 16, No. 3. 1970.

19. Veblen, Thorstein. The Theory of Leisure Class. London: Allen and Unwin. (Reprinted in) 1971. 